\section{JURNAL EKONOMI EFEKTIF}

ISSN : $2622-8882$, E-ISSN : 2622-9935 Jurnal Ekonomi Efektif, Vol. 4, No. 2, Januari 2022 @Prodi Manajemen Fakultas Ekonomi Universitas Pamulang

\title{
PENGARUH PERPUTARAN MODAL KERJA TERHADAP PROFITABILITAS PADA PT INTIKERAMIK ALAMASRI INDONESIA TBK PERIODE 2013-2020
}

\author{
Eva Kania Kurnia Rahmi ${ }^{1}$, Zulfitra ${ }^{2 *}$ \\ Universitas Pamulang, Tangerang Selatan, Banten, Indonesia \\ evamaskan20@gmail.com ${ }^{1}, \underline{\text { dosen01137@unpam.ac.id }{ }^{2 *}}$
}

\begin{abstract}
Manuskrip: Oktober -2021; Ditinjau: November: -2021; Diterima: Desember-2021; Online: Januari -2022; Diterbitkan: Januari-2022
\end{abstract}

\begin{abstract}
ABSTRAK
Penelitian ini bertujuan untuk mengetahui pengaruh Perputaran modal kerja terhadap Profitabilitas pada PT. Intikeramik Alamasri Indonesia Tbk Periode 2013-2020. Metode yang digunakan adalah explanatory research. Teknik analisis menggunakan analisis statistik dengan pengujian regresi, korelasi, determinasi dan uji hipotesis. Hasil penelitian ini variabel Perputaran modal kerja diperoleh nilai rata-rata sebesar 3,552\%. Variabel Profitabilitas diperoleh nilai rata-rata $8,380 \%$. Perputaran modal kerja berpengaruh positif dan signifikan terhadap Profitabilitas dengan nilai persamaan regresi $\mathrm{Y}=1,311+0,002 \mathrm{X}$, dan nilai koefisien korelasi 0,724 atau memiliki tingkat hubungan yang kuat dengan nilai determinasi $52,4 \%$. Uji hipotesis diperoleh signifikansi 0,042<0,05.
\end{abstract}

\section{Kata Kunci: Perputaran Modal Kerja, Profitabilitas}

\begin{abstract}
This study aims to determine the effect of working capital turnover on profitability at PT. Intikeramik Alamasri Indonesia Tbk Period 2013-2020. The method used is explanatory research. The analysis technique uses statistical analysis with regression, correlation, determination and hypothesis testing. The results of the research on the working capital turnover variable obtained an average value of $3.552 \%$. Profitability variable obtained an average value of $8.380 \%$. Working capital turnover has a positive and significant effect on profitability with the value of the regression equation $Y=1.311+0.002 X$, and the value of the correlation coefficient is 0.724 or has a strong relationship with a determination value of $52.4 \%$. Hypothesis testing obtained a significance of $0.042<0.05$.
\end{abstract}

Keywords: Working Capital Turnover, Profitability 


\section{PENDAHULUAN}

\section{A.Latar Belakang Penelitia}

Setiap perusahaan dalam menjalankan operasinya selalu diarahkan pada pencapaian tujuan yang telah ditetapkan. Tujuan utama didirikan perusahaan adalah untuk memaksimalkan kekayaan pemegang saham. Salah satu cara untuk mencapai tujuan perusahaan adalah dengan meningkatkan profitabilitas perusahaan tersebut. Profitabilitas menunjukkan keunggulan perusahaan dalam persaingan bisnis. Semakin tinggi tingkat profitabilitas maka kinerja perusahaan semakin baik.

Profitabilitas adalah kemampuan perusahaan memperoleh laba dalam hubungannya dengan penjualan, total aktiva maupun modal sendiri (Sartono, 2010:122). Bagi perusahaan masalah profitabilitas sangat penting. Bagi pimpinan perusahaan, profitabilitas digunakan sebagai tolak ukur berhasil atau tidak perusahaan yang dipimpinnya. Sedangkan bagi karyawan perusahaan, semakin tinggi profitabilitas yang diperoleh perusahaan, maka ada peluang untuk meningkatkan gaji karyawan. Profitabilitas yang tinggi akan dapat mendukung kegiatan operasional secara maksimal. Tinggi rendahnya profitabilitas dipengaruhi banyak faktor seperti modal kerja.

Modal kerja adalah investasi perusahaan jangka pendek seperti kas, surat berharga, piutang dan inventori atau seluruh aktiva lancar (Putra, 2012). Mengingat pentingnya modal kerja dalam perusahaan, manajer keuangan harus dapat merencanakan dengan baik besarnya jumlah modal kerja yang tepat dan sesuai dengan kebutuhan perusahaan, karena jika terjadi kelebihan atau kekurangan dana hal ini akan mempengaruhi tingkat profitabiltas perusahaan (Supriyadi dan Fazriani, 2011).

Jika perusahaan kelebihan modal kerja akan menyebabkan banyak dana yang menganggur, sehingga dapat memperkecil profitabilitas. Sedangkan apabila kekurangan modal kerja, maka akan menghambat kegiatan operasional perusahaan. Adapun tiga komponen modal kerja yaitu kas, piutang, dan persediaan. Ketiga komponen modal kerja tersebut dapat dikelola dengan cara yang berbeda untuk memaksimalkan profitabilitas atau untuk meningkatkan pertumbuhan perusahaan (Lazaridis dan Tryfonidis, 2010).

PT. Intikeramik Alamasri Industri Tbk (IKAI) didirikan pada tanggal 26 Juni 1991, yang merupakan salah satu produsen ubin porselen terbesar di Indonesia. Perusahaan memulai operasional secara komersial pada bulan Mei 1993, dengan merek dagang "Essenza".

Pengelolaan modal kerja sangat penting karena menyangkut penetapan kebijakan modal kerja maupun pelaksanaan kebijakan modal kerja tersebut dalam operasi seharihari. Manajemen modal kerja berkepentingan terhadap keputusan investasi pada aktiva lancar dan hutang lancar. Terutama mengenai bagaimana menggunakan dan kompisisi keduanya akan mempengaruhi resiko, Weston dan Brigham (1981:245) menjelaskan bahwa manajemen modal kerja adalah investasi perusahaan dalam jangka pendek terdiri dari empat komponen utama yaitu kas, surat-surat berharga (efek), persediaan dan piutang usaha. Dengan modal kerja operasi perusahaan akan berjalan ekonomis dan efisien.

Jumlah keuntungan yang diperoleh secara teratur merupakan salah satu faktor yang penting untuk menilai profitabilitas. Profitabilitas merupakan kemampuan perusahaan untuk menghasilkan laba dalam hubungan penjualan, total aktiva maupun modal sendiri sering digunakan untuk mengatur efisiensi penggunaan modal suatu perusahaan dengan memperbandingkan antara laba dengan modal yang digunakan dalam operasi, oleh karena itu keuntungan yang besar tidak menjamin atau bukan merupakan ukuran bahwa dalam perusahaan tersebut dapat melangsungkan hidupnya 
secara kontinu. Bagi perusahaan pada umumnya masalah rentabilitas lebih penting daripada profit, karena profit yang besar saja belum merupakan ukuran bahwa perusahaan tersebut telah bekerja dengan efisien. Efisien baru dapat diketahui dengan membandingkan laba yang diperoleh dengan kekayaan atau modal yang menghasilkan profit. Oleh karena itu profitabilitas merupakan pencerminan dari efisiensi. Dengan demikian yang harus diperhatikan oleh perusahaan adalah tidak hanya bagaimana usaha untuk memperbesar profit, tetapi yang lebih penting adalah usaha untuk mempertinggi profitabilitasnya.

Berdasarkan kondisi yang telah dipaparakan, penulis tertarik untuk meneliti dan menganalisa pengaruh perubahan Modal Kerja Bersih pada PT. Intikeramik Alamasri Indonesia Tbk. Penelitian dan analisa ini di kembangkan dalam bentuk skripsi yang berjudul "Pengaruh Perputaran Modal Kerja Terhadap Profitabilitas PT. Intikeramik Alamasri Indonesia Tbk."

\section{B. Rumusan Masalah}

1. Bagaimana Perputaran modal kerja pada pada PT. Intikeramik Alamasri Indonesia Tbk ?.

2. Bagaimana Profitabilitas pada PT. Intikeramik Alamasri Indonesia Tbk ?.

3. Adakah pengaruh antara Perputaran modal kerja terhadap Profitabilitas pada PT. Intikeramik Alamasri Indonesia Tbk?.

\section{Tujuan Penelitian}

1. Untuk mengetahui kondisi Perputaran modal kerja pada PT. Intikeramik Alamasri Indonesia Tbk.

2. Untuk mengetahui kondisi Profitabilitas pada PT. Intikeramik Alamasri Indonesia Tbk.

3. Untuk mengetahui pengaruh antara Perputaran modal kerja terhadap Profitabilitas pada PT. Intikeramik Alamasri Indonesia Tbk.

\section{METODE PENELITIAN}

\section{Populasi}

Populasi dalam penelitian ini laporan keuangan PT. Intikeramik Alamasri Indonesia Tbk selama 8 tahun

\section{Sampel}

Teknik pengambilan sampling dalam penelitian ini adalah samplel jenuh, dimana semua anggota populasi dijadikan sebagai sampel. Dengan demikian sampel dalam penelitian ini laporan keuangan PT. Intikeramik Alamasri Indonesia Tbk selama 8 tahun.

\section{Jenis Penelitian}

Jenis penelitian yang dipakai adalah asosiatif, dimana tujuannya adalah untuk mengetahui mencari keterhubungan antara variabel independen terhadap variabel dependennya

\section{Metode Analisis Data}

Dalam menganalisis data digunakan uji validitas, uji reliabilitas, analisis regresi linier sederhana, koefisien korelasi, koefisien determinasi dan uji hipotesis.

\section{HASIL PENELITIAN}

\section{Analisis Deskriptif}

Pada pengujian ini digunakan untuk mengetahui skor minimum dan maksimum skor tertinggi, ratting score dan standar deviasi dari masing-masing variabel. Adapun 
hasilnya sebagai berikut:

Tabel 1. Hasil Analisis Descriptive Statistics

Descriptive Statistics

\begin{tabular}{|lr|r|r|r|r} 
& N & \multicolumn{1}{|c|}{ Minimum } & \multicolumn{1}{c|}{ Maximum } & \multicolumn{1}{c|}{ Mean } & Std. Deviation \\
\hline Perputaran modal kerja (X) & 8 & 3101.2 & 4547.3 & 3522.36 & 537.0497 \\
\hline Profitabilitas (Y) & 8 & 6.4 & 10.9 & 8.380 & 1.4888 \\
\hline Valid N (listwise) & 8 & & & & \\
\hline
\end{tabular}

Perputaran modal kerja diperoleh nilai minimum sebesar 3.101 dan nilai maximum 4.547 dengan rata-rata sebesar 3,552 dengan standar deviasi 537,049. Profitabilitas diperoleh nilai minimum sebesar 6,4 dan nilai maximum 10,9 dengan ratarata sebesar 8,380 dengan standar deviasi 1,488.

\section{Analisis Verifikatif}

Pada analisis ini dimaksudkan untuk mengetahui pengaruh variabel independen terhadap variabel dependen. Adapun hasil pengujian sebagai berikut:

\section{a. Analisis Regresi Linier Sederhana}

Uji regresi ini dimaksudkan untuk mengetahui perubahan variabel dependen jika variabel independen mengalami perubahan. Adapun hasil pengujiannya sebagai berikut:

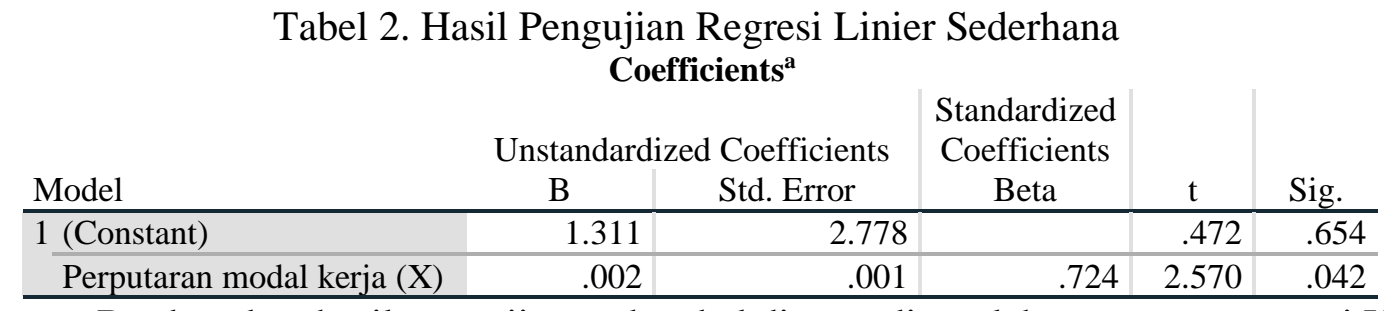

Berdasarkan hasil pengujian pada tabel di atas, diperoleh persamaan regresi $Y$ $=1,311+0,002 X$. Dari persamaan tersebut dijelaskan sebagai berikut:

1) Konstanta sebesar 1,311 diartikan jika Perputaran modal kerja tidak ada, maka telah terdapat nilai Profitabilitas sebesar 1,311 point.

2) Koefisien regresi Perputaran modal kerja sebesar 0,002, angka ini positif artinya setiap ada peningkatan Perputaran modal kerja sebesar 0,002 point maka Profitabilitas juga akan mengalami peningkatan sebesar 0,002 point.

\section{b. Analisis Koefisien Korelasi}

Analisis koefisien korelasi dimaksudkan untuk mengetahui tingkt kekuatan hubungan dari variabel independen terhadap variabel dependen baik secara parsial maupun simultan. Adapun hasil pengujian sebagai berikut:

Tabel 3. Hasil Pengujian Koefisien Korelasi Perputaran modal kerja Terhadap

Profitabilitas.

\section{Correlations $^{\text {b }}$}

\begin{tabular}{llr|r} 
& & Perputaran modal kerja (X1) & Profitabilitas (Y) \\
\hline Perputaran modal kerja (X) & Pearson Correlation & 1 & $.724^{*}$ \\
\cline { 2 - 4 } & Sig. (2-tailed) & & .042 \\
\hline Profitabilitas (Y) & Pearson Correlation & $.724^{*}$ & 1 \\
\cline { 2 - 4 } & Sig. (2-tailed) & .042 & \\
\hline
\end{tabular}

Berdasarkan hasil pengujian diperoleh nilai korelasi sebesar 0,724 artinya Perputaran modal kerja memiliki hubungan yang kuat terhadap Profitabilitas. 


\section{c. Analisis Koefisien Determinasi}

Analisis koefisien determinasi dimaksudkan untuk mengetahui besarnya persentase pengaruh dari variabel independen terhadap variabel dependen. Adapun hasil pengujian sebagai berikut:

Tabel 4. Hasil Pengujian Koefisien Determinasi Perputaran modal kerja Terhadap

Profitabilitas.

Model Summary

\begin{tabular}{ll|r|r|r} 
Model & R & R Square & Adjusted R Square & Std. Error of the Estimate \\
\hline 1 & $.724^{\mathrm{a}}$ & .524 & .445 & 1.1095 \\
\hline
\end{tabular}

Berdasarkan hasil pengujian diperoleh nilai determinasi sebesar 0,524 artinya Perputaran modal kerja memiliki kontribusi pengaruh sebesar 52,4\% terhadap Profitabilitas.

\section{d. Uji Hipotesis}

Pengujian hipotesis dengan uji t digunakan untuk mengetahui hipotesis mana yang diterima. Rumusan hipotesis: Terdapat pengaruh yang signifikan antara Perputaran modal kerja terhadap Profitabilitas.

Tabel 5. Hasil Uji Hipotesis Perputaran modal kerja Terhadap Profitabilitas.

\section{Coefficients $^{\mathrm{a}}$}

\begin{tabular}{|c|c|c|c|c|c|c|}
\hline \multirow{2}{*}{\multicolumn{2}{|c|}{ Model }} & \multicolumn{2}{|c|}{ Unstandardized Coefficients } & \multirow{2}{*}{$\begin{array}{c}\text { Standardized } \\
\text { Coefficients } \\
\text { Beta }\end{array}$} & \multirow[b]{2}{*}{$\mathrm{t}$} & \multirow[b]{2}{*}{ Sig. } \\
\hline & & $\mathrm{B}$ & Std. Error & & & \\
\hline & (Constant) & 1.311 & 2.778 & & .472 & .654 \\
\hline & Perputaran modal kerja (X) & .002 & .001 & .724 & 2.570 & .042 \\
\hline
\end{tabular}

Berdasarkan hasil pengujian pada tabel di atas, diperoleh nilai thitung $>\mathrm{t}$ tabel atau $(2,570>2,447)$, dengan demikian hipotesis yang diajukan bahwa terdapat pengaruh yang signifikan atara Perputaran modal kerja terhadap Profitabilitas diterima.

\section{Pembahasan Hasil Penelitian}

\section{Kondisi Jawaban Responden Variabel Perputaran modal kerja}

Berdasarkan data empiris dan analisis data, variabel Perputaran modal kerja diperoleh nilai rata-rata per tahun sebesar $3,552 \%$.

\section{Kondisi Jawaban Responden Variabel Profitabilitas}

Berdasarkan data empiris dan analisis data, variabel Profitabilitas diperoleh nilai rata-rata per tahun sebesar $8,380 \%$.

\section{Pengaruh Perputaran modal kerja Terhadap Profitabilitas}

Perputaran modal kerja berpengaruh signifikan terhadap Profitabilitas dengan persamaan regresi $\mathrm{Y}=1,311+0,002 \mathrm{X}$, nilai korelasi sebesar 0,724 atau memiliki hubungan yang kuat dengan kontribusi pengaruh sebesar 52,4\%. Pengujian hipotesis diperoleh nilai $t$ hitung $>\mathrm{t}$ tabel atau $(2,570>2,447)$. Dengan demikian hipotesis yang diajukan bahwa terdapat berpengaruh signifikan antara Perputaran modal kerja terhadap Profitabilitas diterima.

\section{KESIMPULAN DAN SARAN}

\section{Kesimpulan}

a. Variabel Perputaran modal kerja diperoleh ratting score sebesar 3,552 berada di rentang skala 3,40 - 4,19 dengan kriteria baik atau setuju. 
b. Variabel Profitabilitas diperoleh ratting score sebesar 8,380 berada di rentang skala 3,40 - 4,19 dengan kriteria baik atau setuju.

c. Perputaran modal kerja berpengaruh signifikan terhadap Profitabilitas dengan persamaan regresi $\mathrm{Y}=1,311+0,002 \mathrm{X}$, nilai korelasi sebesar 0,724 atau kuat dan kontribusi pengaruh sebesar 52,4\% sedangkan sisanya sebesar 57,9\% dipengaruhi faktor lain. Uji hipotesis diperoleh nilai t hitung $>t$ tabel atau $(2,570>2,447)$.

\section{Saran}

Berdasarkan hasil penelitian dan kesimpulan, ada beberapa hal yang dapat dijadikan masukan atau saran dalam penelitian ini, adalah sebagai berikut:

a. Perkembangan perputaran modal kerja yang terdapat pada PT Anabatic Technologies Tbk cukup baik meskipun terjadi penurunan pada tahun 2018. Diharapkan untuk kedepannya perusahaan agar terus memperbaiki kinerja karyawan, penggunaan operasional perusahaan, neraca perusahaan dan L/R perusahaan.

b. Meningkatkan modal kerja secara efektif dan efisien sehingga akan lebih menguntungkan perusahaan.

c. Untuk penelitian selanjutya agar ditambahkan variabel lain agar hasil menjadi lebih baik

\section{DAFTAR PUSTAKA}

Agus Harjito \& Martono, (2010) "Manajemen Keuangan" Yogyakarta: Penerbit Ekonisia. Agus Sartono. (2010). "Manajemen Keuangan Toeri dan Aplikasi", Edisi keempat, Yogyakarta: Penerbit BPFE.

Algifari. (2015). “Analisis Regresi untuk Bisnis dan Ekonomi”. Yogyakarta: BPFE.

Arikunto, Suharsimi (2014). "Prosedur Penelitian Suatu Pendekatan Praktek". Jakarta: Rineka Cipta.

Bambang Riyanto, (2011). "Dasar-dasar Pembelanjaan Perusahaan”. Edisi ke empat, BPFE Yogyakarta.

Fahmi, Irham (2012), "Pengantar Manajemen Keuangan" Cetakan pertama. Bandung: Penerbit Alfabeta.

Imam Ghozali (2017). "Aplikasi Analisis Multivariate Dengan Program SPSS”. Edisi Kelima. Semarang: Badan Penerbit Undip.

Istijanto (2014) "Riset Sumber Daya Manusia". Jakarta: PT. Gramedia Pustaka

Kasmir. (2012) "Pengantar Manajemen Keuangan”, Edisi Pertama, Cetakan kedua, Jakarta: Prenada Media.

Martono dan Agus Harjito, (2011). "Manajemen Keuangan”, Jakarta: Penerbit Ekonisia..

Munawir (2010), “Analisis Laporan Keuangan”, Edisi Ke Empat, Penerbit Liberty, Yogyakarta.

Santoso, Singgih (2015). "Menguasai Statistik Multivariat". Jakarta: PT Elex Media Komputindo.

Sartono, "Manajemen Keuangan Aplikasi Dan Teori", Edisi Keempat, BPFE, Yogyakarta, 2008.

Sawir, (2003). “Analisis Kinerja Keuangan dan Perencanaan Keuangan Perusahaan”, Cetakan ketiga, Jakarta: Penerbit PT. Gramedia Pustaka Utama.

Sugiyarso, G. dan F. Winarni, "Manajemen Keuangan (Pemahaman Laporan Keuangan, Pengelolaan Aktiva, Kewajiban dan Modal serta Pengukuran

Sugiyono (2017), "Metode Penelitian Administrasi : dilengkapi dengan Metode R \& D". Bandung: Alfabeta. 